\title{
Modelagem matemática aplicada ao Ensino de Física a partir de um experimento de Mecânica Aplicada no Projeto Astroem III - UFABC
}

\author{
Claudia Celeste Celestino ${ }^{1}$ \\ Centro de Engenharia, Modelagem e Ciências Sociais, UFABC, Santo André, SP \\ Wesley Góis ${ }^{2}$ \\ Centro de Engenharia, Modelagem e Ciências Sociais, UFABC, Santo André, SP \\ Claudia de Oliveira Lozada ${ }^{3}$ \\ Centro de Engenharia, Modelagem e Ciências Sociais, UFABC, Santo André, SP \\ Matheus Pantrigo Licarião Barbosa ${ }^{4}$ \\ Bacharelado em Ciência e Tecnologia, UFABC, Santo André
}

Resumo. Neste trabalho apresentamos os resultados de uma pesquisa qualitativa centrada em modelagem matemática aplicada ao Ensino de Física desenvolvida a partir de experimentos em um projeto de extensão da Universidade Federal do ABC. Os resultados demonstraram que os experimentos podem contribuir significativamente para a compreensão do fenômeno físico e viabilizar a modelagem matemática de uma forma mais interativa, além de possibilitar a interdisciplinaridade e a ressignificação de conceitos matemáticos. Palavras-chave. Modelagem Matemática, Ensino de Física, Experimentação, Projeto Astroem

\section{Introdução}

As aulas de Física do Ensino Médio em grande parte das escolas brasileiras, sobretudo, aquelas da rede pública consistem em aulas teóricas e problemas-tipo, como abordado por Lozada [8], para fixação do mecanismo de resolução e operacionalização das "fórmulas" que descrevem os fenômenos físicos. Como as "fórmulas" são tratadas como fonte primaz da resolução da situação-problema, as variáveis que as compõem não apresentam sentido físico para o aluno, e sim mera representação literal para substituição numérica com os dados retirados do enunciado. Ao se colocar uma situação-problema na qual o aluno não possui dados suficientes para substituir em "fórmulas" conhecidas e terá que desenvolver o modelo matemático que represente o fenômeno, é comum que desistam de tentar resolver a questão.

\footnotetext{
${ }^{1}$ claudia.celeste@ufabc.edu.br

${ }^{2}$ wesley.gois@ufabc.edu.br

${ }^{3}$ cld.lozada@gmail.com

${ }^{4}$ matheus.pantrigo@aluno.ufabc.edu.br
} 
Percebe-se pouca familiaridade com a linguagem algébrica que representa os modelos matemáticos que descrevem fenômenos físicos, o que implica em dificuldade na conversão dos registros semióticos, como pontuam estudos sobre o tema realizados por Duval e também por Souza $[5,10]$. Para os alunos, o grau de abstração é maior em situações como esta na qual há necessidade de modelagem matemática do fenômeno estudado. Este tipo de modelagem também pode ser realizada com softwares ou por meio de experimentação explicitados em trabalhos realizados por autores e seus colaboradores como Lozada, Morrone e Heinen $[6,7,9]$, constituindo alternativas para se tornar a aprendizagem significativa. Vários autores têm apresentado pesquisas que geram dissertações e teses na área de ensino e relatos de experiência de atividades propostas a partir da experimentação nas aulas de Física, ocasiões nas quais os alunos tem a oportunidade de elaborar os modelos matemáticos, partindo muitas vezes de perspectivas de ensino por investigação. Neste sentido, este trabalho tem como objetivo central relatar os resultados de uma pesquisa qualitativa sobre modelagem matemática aplicada ao Ensino de Física em aulas de um projeto de extensão desenvolvido por um grupo de professores e pesquisadores da Engenharia Aeroespacial da Universidade Federal do ABC.

\section{O Projeto Astroem III e o Ensino de Física}

O Projeto Astroem III foi desenvolvido em 2015 em uma escola da rede pública estadual da região do Grande ABC. Atualmente está na sua sexta edição. É uma iniciativa da Pró-Reitoria de Extensão e Cultura da Universidade Federal do ABC coordenada por professores e pesquisadores da Engenharia Aeroespacial. Tem como objetivo contribuir para a melhoria do Ensino de Ciências/Física na Educação Básica, promovendo a alfabetização científica e a popularização da Ciência por meio de quatro eixos: Astronáutica, Aeronáutica, Astronomia e Mecânica Aplicada. São desenvolvidas aulas práticas e teóricas, guiadas pelos alunos do Bacharelado em Ciência e Tecnologia e Engenharias da UFABC sob a supervisão da coordenação do projeto.

O objetivo de todos os experimentos desenvolvidos no Projeto Astroem no ano de 2015, visou principalmente, a integração dos conteúdos relacionados com a matriz curricular do Ensino Médio e Ensino Fundamental II (Linguagens e Códigos e suas Tecnologias, Ciências da Natureza, Matemática e suas Tecnologias e Ciências Humanas e suas Tecnologias) apresentando as relações desses conteúdos com as questões da Engenharia Aeroespacial. Especificamente, nas atividades do Astroem com alunos do Ensino Médio e Ensino Fundamental II, alguns dos experimentos foram estruturados para trabalhar a interdisciplinaridade dentro das disciplinas que compõem o eixo das Ciências da Natureza, Matemática e suas Tecnologias. Neste item, dentre um conjunto diversificado de experimentos, será relatado um destes com ênfase na Mecânica Aplicada desenvolvendo a modelagem. 


\section{A pesquisa qualitativa}

Uma das áreas de atuação do Projeto Astroem é a Mecânica Aplicada. Essa temática foi proposta para trabalhar com os alunos do Ensino Médio e Fundamental II questões relacionadas à observação de fenômenos físicos mecânicos, como descrevê-los matematicamente (modelagem) e entender como estes fenômenos e as tecnologias resultantes desse ramo estão presentes no cotidiano desses alunos.

Um dos experimentos relacionados com a Mecânica Aplicada no Projeto Astroem, trabalhou com a plataforma LEGO Mindstorms. Os kits para a realização desta atividade foram cedidos pela Universidade Federal do ABC. Abaixo, vemos o Kit e o robô Lego montado.

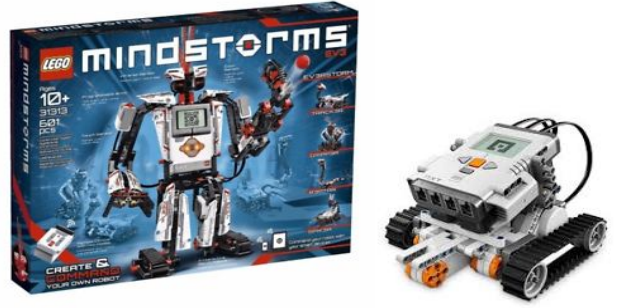

Figura 1: Kit Lego Mindstorms

Um desafio inicial apresentado ao grupo de alunos do Ensino Médio de uma escola estadual do Grande ABC foi desenvolver uma lógica de programação na plataforma Lego Mindstorms para que o robô criado por eles percorresse um quadrado de certa dimensão com velocidade constante, e também percorresse um metro em linha reta.

Para execução dessa atividade, os alunos da Escola foram divididos em equipes. Cada equipe recebeu um manual do experimento, detalhando todos os passos da atividade. Vale lembrar que no final da prática cada grupo de alunos respondeu um conjunto de questões relacionadas com o experimento.

Em um primeiro momento, os alunos não conseguiam enxergar como as disciplinas de Ciências da Natureza, Matemática e suas Tecnologias poderiam ser integradas com essa atividade e foi notória a mudança de comportamento dos alunos após a execução da mesma.

Um dos grandes desafios foi superado quando os alunos perceberam que precisariam do comprimento da roda do robô e da dimensão do lado do quadrado para a finalização da programação. A pergunta "qual o comprimento da circunferência?" foi prontamente levantada por eles, como pode se ver pela ilustração - figura 2. 


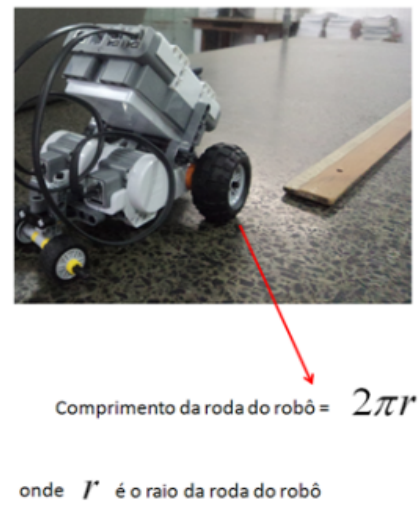

Figura 2: Medida do raio da roda do robô e cálculo do comprimento da mesma

Nesse momento, os monitores do Astroem apontaram a importância dos conhecimentos de geometria plana e espacial para aquele desafio e, desta forma, introduziram e ressaltaram a integração de um conteúdo específico da Matemática com Robótica e Física. Os monitores do Astroem também salientaram a importância da Matemática, da Robótica e da Física para as pesquisas e produtos na Engenharia Aeroespacial.

Na sequência desta prática, com o objetivo de verificar experimentalmente a equação que descreve a velocidade média e as características do movimento retilíneo uniforme (MRU), os alunos fizeram a coleta de dados da distância percorrida e do tempo, utilizando o movimento do robô automatizado. Após a obtenção destes dados dispostos em tabelas, eles traçaram curvas (distância percorrida pelo robô x tempo) utilizando as unidades do Sistema Internacional (SI), e calcularam a velocidade média de cada trecho, utilizando a equação 1. Um exemplo apresentado por um dos grupos pode ser observado na figura 3.

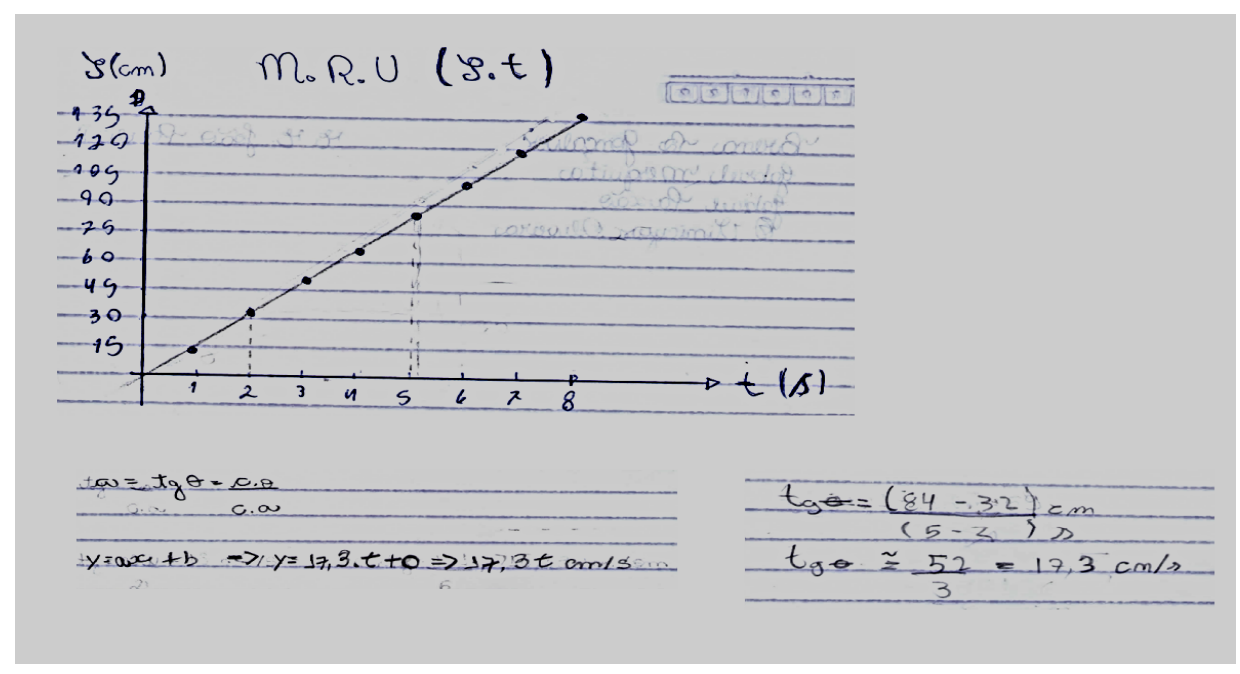

Figura 3: Coleta de dados e representação gráfica do movimento do robô desenvolvida por uma das equipes de alunos 
Com a utilização deste experimento foi possível ensinar ou rever o tema "gráficos de função de $1^{\circ}$ grau" de modo que os alunos percebessem a característica deste tipo de função representado no MRU.

$$
\text { Velocidade Média }=\frac{\Delta S}{\Delta t}
$$

Em que:

$\Delta S$ É o espaço percorrido; $\Delta t$ É o intervalo de tempo.

Os alunos puderam compreender como o modelo matemático $S=S o+v \cdot t$ tem relação com a função do $1^{\circ}$ grau $y=a x+b$, identificando coeficientes e variáveis e seu sentido físico e matemático, estabelecendo uma relação interdisciplinar. Anteriormente, este modelo do MRU era lembrado como a "fórmula do sorvete", sendo memorizado sem nenhum significado.

\section{Considerações Finais}

A aplicação desse experimento foi muito interessante, pois possibilitou a todos os alunos participar ativamente no processo de aprendizagem. Além do mais, a atividade teve enfoque interdisciplinar possibilitando estabelecer relações entre os conteúdos de Matemática e Física.

Os alunos puderam visualizar e modelar um fenômeno físico mecânico (cinemática do robô da plataforma Lego Mindstorms) sendo necessário programar o robô (lógica de programação) com alguns conceitos da Matemática. Desta forma, apresentaram maior desenvoltura com as operações matemáticas básicas e conteúdos como função do $1^{\circ}$ grau e sua representação gráfica, assim como aspectos geométricos (coeficiente angular que corresponde à taxa de variação, e consequentemente ao cálculo da velocidade, e sua visualização e determinação pelas relações trigonométricas do triângulo retângulo definido pela reta). O movimento do robô possibilitou a compreensão da velocidade média e o sentido físico da razão entre as grandezas físicas do espaço percorrido num determinado intervalo de tempo e o significado de suas variáveis inicial e final. Outro aspecto relevante foi a ressignificação do Movimento Retilíneo Uniforme, a característica da velocidade como constante e os movimentos progressivo e retrógrado, além das unidades físicas e sua utilização correta.

Na conversão do registro semiótico, os alunos compreenderam o papel de cada variável na representação do modelo matemático do movimento retilíneo uniforme, decorrente do modelo matemático da velocidade média e o papel do formalismo na representação algébrica. A matemática apresenta um caráter operacional/ferramental e técnico na Física, sendo necessário compreender essa transitividade das notações matemáticas, como colocam os estudos de Concheti. [4]

Houve maior engajamento e participação na atividade, uma vez que os alunos puderam montar o robô, colocá-lo em movimento e realizar as medições, o que oportunizou o levantamento de hipóteses, estabelecimento de relações entre as variáveis estudadas no fenômeno físico, argumentação, testes e validações, típicos de um ciclo de modelagem matemática, como descrevem os trabalhos de Bassanezi [2] e Biembengut e Hein [3]. 
A aprendizagem foi verificada observando-se as respostas dos alunos a todas as questões apresentadas no questionário final da atividade.

Portanto, atividades com este teor, no caso experimental e interdisciplinar, mostram-se mais frutíferas, colocando o aluno como protagonista do processo ensino-aprendizagem. O professor atua como mediador estimulando as indagações e pesquisas, sem fornecer respostas prontas e padronizadas e deixa de dar ênfase a um excessivo processo de matematização. Sendo assim, é necessário que o professor planeje este tipo de atividade, oriente a formação em grupos e estabeleça contato com professores de outras disciplinas para efetivar a interdisciplinaridade em outras aulas sobre os conteúdos conexos. Desta forma, consegue reconfigurar a sala de aula, transformando-o num ambiente de aprendizagem para modelagem matemática, como pontua Barbosa [1] em sua tese, tornando-o mais atrativo e interativo.

\section{Referências}

[1] J. C. Barbosa. Modelagem Matemática: concepções e experiências de futuros professores. Tese de Doutorado, Instituto de Geociências e Ciências Exatas, Universidade Estadual Paulista, 2001

[2] R. C. Bassanezi, Ensino-aprendizagem com Modelagem Matemática. Editora Contexto, São Paulo, 2004.

[3] M. S. Biembengut and N. Hein. Modelagem Matemática no Ensino. Editora Contexto, São Paulo, 2005.

[4] A. F. Concheti, A pluralidade da relação entre a física e a matemática em um curso inicial de licenciatura em física. Dissertação de Mestrado, Universidade de São Paulo, 2014.

[5] R. Duval. Registros de representação semiótica e funcionamento cognitivo da compreensão em matemática. In Aprendizagem em matemática: registros de representação semiótica, Papirus, Campinas, 2011.

[6] C. A. Heinen, M. J. H. Rehfeldt, I. G. Neide, W. J. Böckel and R. I. König. Atividades experimentais e modelagem matemática: uma prática realizada com alunos do ensino médio politécnico. Caderno pedagógico, Lajeado, 13: 139-155, 2016. http://dx.doi.org/10.22410/issn.1983-0882.v13i1a2016.992

[7] C. O. Lozada, M.S.T. Araújo, W. Morrone and L. H. Amaral. A Modelagem Matemática aplicada ao Ensino de Física no Ensino Médio. Revista Logos, v. 14: 2-12, 2006 .

[8] C. O. Lozada. Alternativas de modelagem matemática aplicada ao contexto do ensino de física: a relevância do trabalho interdisciplinar entre matemática e física. In Anais do Encontro Nacional de Educação Matemática (IX ENEM), Belo Horizonte, Minas Gerais, Brasil, 2007. 
[9] W. Morrone, C. O. Lozada, L. H. Amaral and M. S. T. Araújo. Conceituando corrente e a resistência elétrica por meio de sensações utilizando materiais do dia-a-dia: um experimento para aprendizagem significativa de alunos do Ensino Médio. In Anais do Simpósio Nacional de Ensino de Física (XVII SNEF). São Luís, Maranhão, 2007.

[10] E. S. R. Souza. Modelagem matemática no ensino de física: registros de representação semiótica, Dissertação de Mestrado, UFPA, 2010. 